\title{
Guangdong Export-Oriented Economic Development Research
}

\author{
Biao Xiong ${ }^{1, a}$
}

${ }^{1}$ School of Economics and Commerce, South China University of Technology, Guangzhou, Guangdong, China

a364288838@qq.com

Keywords: export-oriented economy; foreign trade; utilization of foreign capital

\begin{abstract}
Ever since practicing the policy of reformation and opening, the economic development of Guangdong province has roughly experienced the three stages: the take-off stage (1979-1991),the accelerating development stage (1992-2002) and the scientific development stage (2003-now). Guangdong Province has made tremendous achievements in the process of reform and opening up more than 30 years, The role of export-oriented economic development strategy is more and more important, and it is really significant. This paper will research the export-oriented economic development in Guangdong province.

In this paper, we will use the real, full data information to research the export-oriented economic development in Guangdong province. Firstly, we will analyze the historical development and the basic meaning of export-oriented economy in Guangdong province, and the achievements in the economic development of Guangdong province. Secondly, analyzing the status of Guangdong province export-oriented economy, the growth trend and characteristics and finding the problems, identifying the cause of the problems. Finally, the summary of the full text, and put forward four countermeasures to promote the further development of export-oriented economy in Guangdong province:(1) co-ordinate domestic and international markets, it is necessary to actively expand the domestic market, the second is to diversify our export markets, to avoid over-reliance on a single or a few major markets; (2) to improve the trade structure, improve the quality of traded goods, insist on the implementation of the industrial structure and upgrading; (3) to encourage private enterprise to develop; (4)to increase international efforts to train personnel in foreign trade .
\end{abstract}

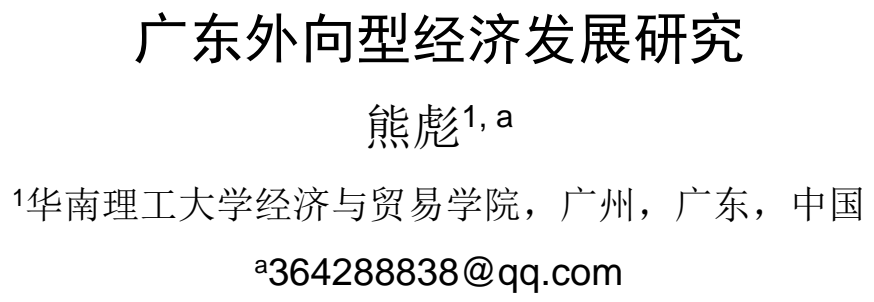

关键词: 外向型经济; 对外贸易; 利用外资

中文摘要. 自从实行改革开放政策以来，广东省的经济发展大致经历了起飞阶段（1979-1991 年）、加速发展阶段（1992-2002年）以及科学发展阶段（2003年-现在）这三个阶段, 广东 省30多年来在改革开放进程中取得了巨大的成就，外向型经济战略作用逐步提升，而且举足 轻重, 本文将研究广东省的外向型经济发展情况。

本文采用真实、充分的数据资料，首先分析广东省外向型经济的历史发展过程、基本涵 义、广东省经济发展所取得的成就; 其次, 通过分析广东省外向型经济的现状、增长的基本 态势和特征, 发现其中存在的问题, 并找出问题的原因。最后, 对全文进行总结, 并据此提 出进一步发展广东省外向型经济、促进广东省经济又好又快发展的四个对策建议: (1) 统筹 
国内国际两个市场, 一是要积极扩大国内市场, 二是要坚持出口市场多元化, 避免对单个或 少数主要市场的过度依赖; (2) 改善贸易结构, 提高贸易商品品质, 坚持推行产业结构升级;

（3）鼓励私营企业发展;

（4）加大对外贸易方面的国际化人才培养力度。

\section{1. 引言}

自从实行改革开放政策以来，广东省30多年来在改革开放进程中取得了巨大的成就，外 向型经济战略在广东省经济发展的过程中发挥着越来越重要的作用。广东省的实践证明: 一 个地区的经济的开放度越高, 那这个地区的经济的发展就越好, 继续实行改革开放政策, 才 能让广东省的经济达到新高度。

自从实行改革开放政策以来, 广东省大力推行外向型发展战略, 对外开放程度逐步提高, 非常积极参加国际竞争, 对于来自国外的产业转移, 努力应对, 使得广东省的经济快速增长, 是我国外向型经济发展最快的省份。1980年, 深圳市、珠海市以及汕头市被设立为经济特区, 进入二十一世纪以后，在2001年，中国正式成为世界贸易组织的正式成员国，在加入WTO的 巨大历史机遇以及越来越深入的经济全球化背景下, 广东省进一步加大对外开放程度, 使得 可以在更好的环境下参加国际分工, 并努力保持经济的平稳快速发展。期间经历了1997年的 亚洲金融危机和2008年全球金融危机, 这两次大范围和大规模的金融危机对中国的经济发展 产生了非常巨大的冲击, 尤其是2008年的全球金融危机对我国的外向型经济发展和金融领域 产生了极大的负面影响。广东省作为全国的出口大省, 受到的影响比其他兄弟省份更大, 这 对广东省的外向型经济发展是一次重要的考验, 不过从另一个角度看, 2008年的金融危机又 可能是一次重要的机会——迫使广东省的出口企业对出口结构进行转型升级。

\section{2. 相关文献综述}

郑英隆 (1988) 认为, 信息产业体系对整个外向型经济体系的运转有导向传动的作用和 功能。信息产业体系对广东的外向型经济发展具有重要的导向传动的作用, 外向型经济的特 性要求广东必须尽快建立信息产业体系, 以信息产业体系带动广东的外向型经济的运转。王 宏（2009）认为外商直接投资拉动经济增长、促进外贸进出口、带动产业结构的优化、推动 固定资产投资和促进就业, 在广东外向型经济发展的过程中起着助推器的作用。邱志钢 (1989) 认为发展外向型经济, 必须充分利用和发展对外金融。外汇是外向型经济的对外贸易过程中 的重要结算资金, 在对外贸易中, 有着重要的结算作用。谢守红（2003）认为广东省是我国 改革开放的排头兵, 外向型经济的发展非常迅猛, 速度很快, 但是不同地区之间的发展相当 不协调, 由于开放程度的差别以及各地区经济环境和社会条件的不同, 广东省不同地区之间 的外向型经济发展差别非常大。

陈平，李凯（2008）认为，人民币的渐进升值，长期内对中国进出口厂商都是有益的， 我们完全不必为人民币升值 “杞人忧天”, 我们应该利用人民币升值这个契机, 通过产业升 级, 实现经济更好的发展。谭作平, 郑少智（1990）认为广东在前几年的实践探索中, 逐步 建立了一个既和当下的体制相协调又能初步体现市场性特点的宏观经济调控体系, 不过在新 形势下, 我国的宏观调控将面临两大重任: 一是在国内经济模式转变过程中, 及时修正宏观 经济活动出现的偏差以及重大比例关系的不协调, 同时在实践中重新构建能体现新的经济模 式要求的有效宏观调控体系; 二是根据世界性产业结构和国际市场变化的趋势和特点, 制定 明确的产业政策及相应的投资政策，采取有效措施，适当地调整并控制产业的存量和增量， 确保能够正常实施外向型的经济发展战略。 


\section{3. 有关外向型经济的内涵与特征}

\section{1 外向型经济的涵义}

外向型经济就是指一国（或者地区）为了促进该国（或者地区）的经济发展，以国际市 场的需求为导向, 以加大出口为中心, 根据比较优势理论, 积极参与国际分工, 所建立起来 的经济结构、经济运行机制及经济运行体系的总和。

外向型经济与 “内向型经济” 是相互对称的, 它和国际市场之间有很重要的关系, 是一种 被普遍采用的经济模式, 外向型经济一般分广义和狭义两种, 本文中所指的外向型经济, 若 无特别说明, 都是指广义的范畴。

\section{2 外向型经济的理论依据}

学术上一般认为, 外向型经济理论首先是由亚当 - 斯密提出的, 他的绝对成本理论虽然 有很多局限性, 在当代看来也没有现实的推行意义, 但是确实是外向型经济理论的开篇之作。 外向型经济理论经过李嘉图发表的比较成本理论, 赫克歇尔-俄林发表的要素禀赋理论以及现 在国际竞争优势理论等阶段的不断发展, 在理论上虽然有较大发展, 但是都没有取得根本性 的突破。这些理论大都以比较优势作为发展外向型经济、参与国际分工的依据, 但比较优势 本身也存在一定的缺陷和不完善之处。

外向型经济在某种程度还是要根据比较优势来发展的, 但也要看到比较优势的一些不利 方面, 加快产业结构优化升级, 避免一些不必要经过的障碍, 在比较优势弱化的局面形成一 开始, 就要谋划好未来的发展, 突破固有的优势, 提炼出新的优势, 从而可以保持外向型经 济的平稳发展, 从中获取更多的利益。

\section{3 外向型经济的主要特征}

外向型经济的主要特征有先进性、合理性以及风险性。

1、先进性。对一些不发达的国家或者地区来说, 没有强有力的生产力和积极开放的经济 体制结构做基础, 它们都选择了封闭的经济发展模式, 和经济体系外部的联系不多, 不能够 充分发挥当地的比较优势, 而对于外向型经济而言, 面对国际市场压力, 必须加强技术进步, 使得经济能够向更高的层次发展。

2、合理性。众所周知, 外向型经济的活动跨越了国别, 在全球范围内进行着经济活动, 使得全球的资源得以流通，并且可以更合理地配置这些资源。

3、风险性。由于外向型经济活动的触角已经伸向了国外, 对国际市场具有较高的依赖性, 受世界经济变化的影响较大, 很容易受到国际垄断资本的控制, 所以说外向型经济的风险性 大于封闭性的经济，相当于用比较高的代价来换取经济的发展成效。

对于中国而言, 外向型经济的特征主要有: 1. 政府主导型经济, 2.沿海地区发展比其他内 陆地区要快，3.发展外向型经济必须兼顾对内对外开放、促进两者的协调发展。

\section{4. 广东省外向型经济发展现状及特征}

\section{1 广东省外向型经济发展总体概况}

虽然2009年是广东省最近10年经济发展比较艰苦的一年，但是在面对非常复杂、不利的 宏观经济环境时, 全省上下坚持以科学发展观为指导, 继续实施 “一个战略” , 突出 “两个 重点” , 着力 “三个提升” , 使得广东省的经济得到回升, 并且有向好发展的趋势, 2009年 实现生产总值39482.56亿元, 比2008年增长了7.3\%, 其中第一产业2010.27亿元, 增长 $1.89 \%$, 第二产业19419.7亿元, 增长 $4.96 \%$, 第三产业18052.59亿元, 增长 $10.61 \%$ 。第三产业的异军 突起, 为广东省生产总值的又好又快发展和稳定增长打下了坚实的基础。从广东省的人均生 产总值来看, 2000 年人均生产总值为 14324 元/人, 2003 年达到了 20515 元/人, 到 2006 年人均生 
产总值攻破了三万元关口，达到了 33034 元/人，到2008年人均生产总值攻破了四万元关口， 达到了 44510 元/人，2009年更是达到了 47194 元/人的新高度。

步入二十一世纪后，广东省的经济保持了积极高速的增长，GDP从2000年的10741.25亿 元增至2009年的39482.56亿元，10年间增长了 $267.58 \%$ ，其中第一产业由2000年的986.32元增 至2009年的2010.27亿元，增长了 $103.82 \%$ ，第二产业由2000年的4999.51亿元增至2009年的 19419.7亿元, 增长了 $288.43 \%$, 第三产业由2000年的4755.42亿元增至2009年的18052.59亿元, 增长 $279.62 \%$, 广东省的GDP及三次产业生产总值的变化如图1所示。

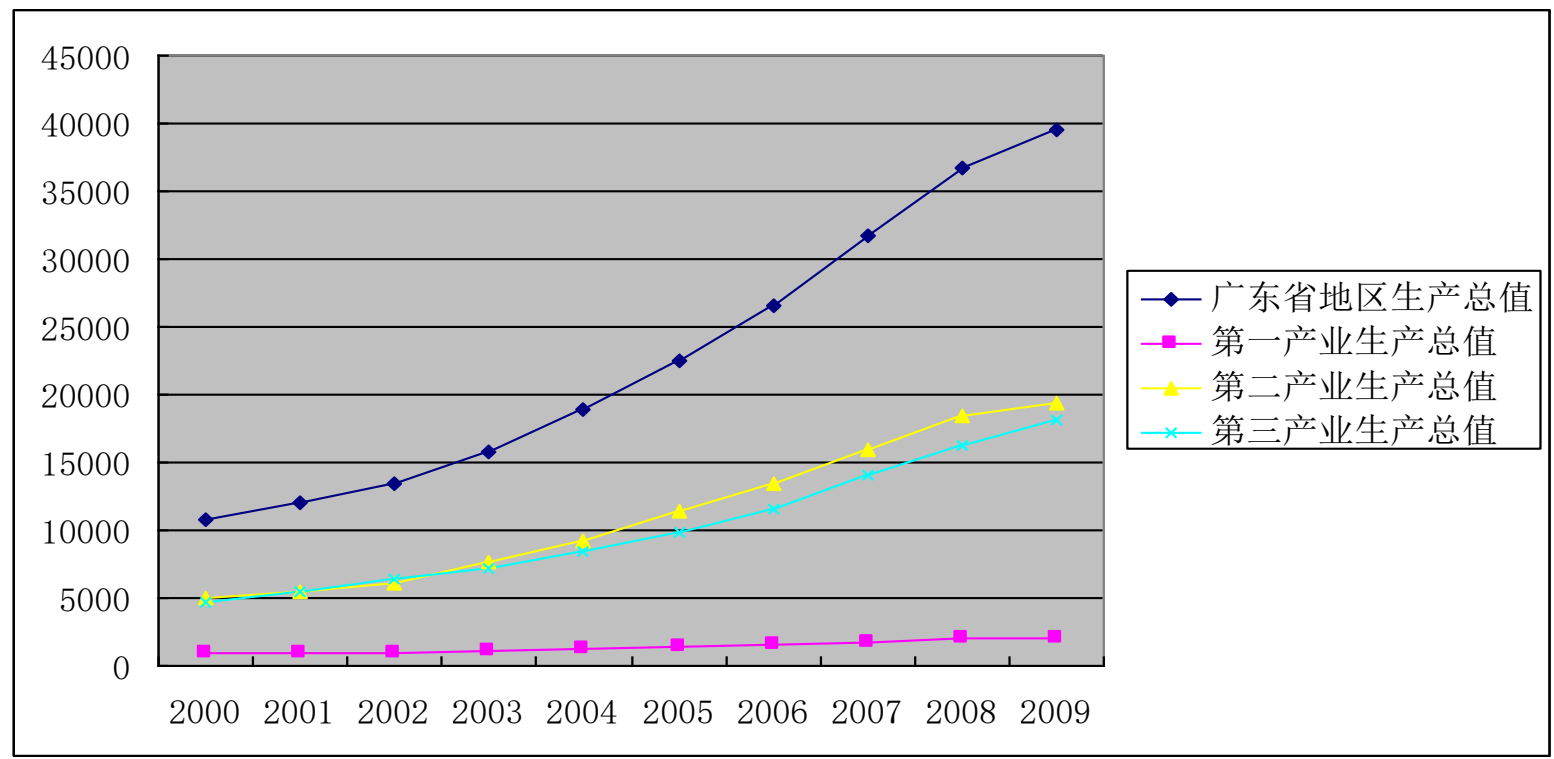

图1 2000-2009年广东省GDP总值及构成（单位：亿元）

近10年来, 广东省的经济结构发生了十分重要的变化, 如图4-2所示, 第一产业占比从2000 年的 $9.2 \%$ 降至2009年的 $5.1 \%$ ，第二产业的占比从 2000 年的 $46.5 \%$ 增至 2009 年的 $49.2 \%$, 并基本 保持稳定, 第三产业的占比由2000年的44.3增至2009年的45.7\%, 并保持着上升态势, 广东省 自2000年以来第一、第二、第三产业生产总值在全省生产总值中的占比情况如图2所示。

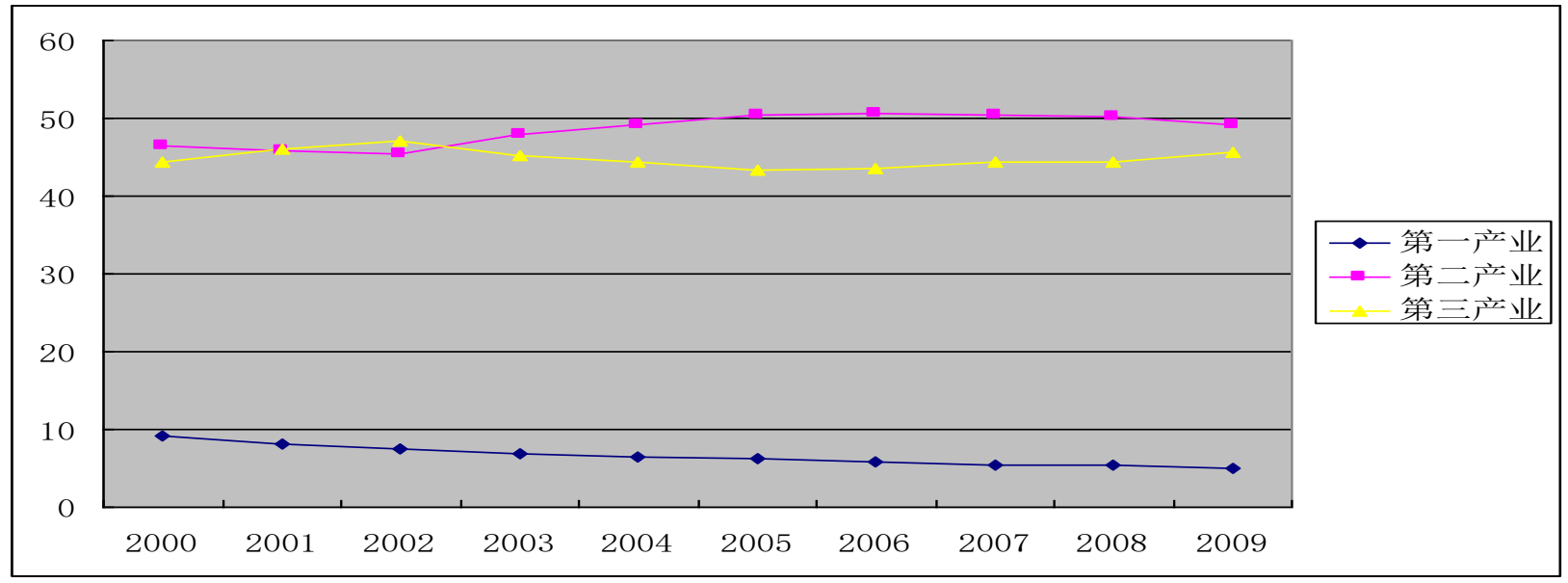

图2 广东省2000-2009年第一、第二、第三产业在GDP所占比重

\section{2 进出口发展现状及特征}

\subsection{1 进出口总量快速增长}

2009年，广东省进出口总额为61111817万美元，和2000年的 17010600 万美元相比增长了 $259.26 \%$ ，其中一般贸易额由 2000 年的 3829100 万美元增至 2009 年的 19881965 万美元，增长了 $419.23 \%$, 出口由 2000 年的 9191900 万美元增至 2009 年的 35895578 万美元, 增长了 $290.51 \%$, 
其中一般贸易额由 2000 年的 1743600 万美元增至2009年的10981638万美元，增长了 529.83\%， 进口由 2000年的7818700万美元增至2009年的25216239万美元, 增长了 $222.51 \%$, 其中一般贸 易额由 2000 年的 2085500 万美元增至 2009 年的 8900325 万美元，增长了 $326.77 \%$ 。

4.2.2 外贸依存度发展现状及特征

1、外贸依存度呈现先上升后下降的态势, 而且2009年出现了大幅度下降

在2000年至2009年期间，外贸依存度呈现出先上升后下降的态势，2004年达到最高点 $156.6932 \%$ 。但从 2008 年开始, 广东省的外贸依存度出现了大幅度下降，2009年甚至一度下降 到 $105.7329 \%$, 广东省外贸依存度的下降与美元汇率的下降和 2008 年全球金融危机有很大的关 系。人民币升值造成的美元汇率的下降, 导致以人民币为单位表示的进出口额下降了, 进而 导致广东省外贸依存度的下降。而2008年和2009年外贸依存度的大幅度下降, 主要是由于2008 年金融危机的冲击导致的, 对广东省的出口企业产生了非常不利的影响, 出口受到严重影响, 造成了外贸依存度的大幅度下降。美元汇率的下降和金融危机的双重作用, 使得出口和进出 口受到极大的负面影响, 最终造成了外贸依存度的大幅度下降。

2、外贸出口依存度持续上升，但2008年开始明显下降

广东省外贸出口依存度持续上升，这与广东省的比较优势相符合，本质上反映了广东省 在国际市场上的竞争力不断提高, 表明广东省在国际分工体系中扮演了越来越重要的角色。 广东省的外贸出口依存度从 2000 年的 $70.84 \%$, 上升到 2007 年的 $85.84 \%$, 提高了将近 15 个百分 点, 其中 2006 年达到最高, 为 $88.68 \%$, 表明7年间在广东省的经济发展中, 国外需求的拉动作 用不断上升。2008年的金融危机, 使广东省外贸出口总额在 2009 年首次出现负增长, 使得广 东省外贸出口依存度在 2009 年下降到 $62.10 \%$, 某种意义上影响到广东省经济的持续快速发展。

3 、外贸进口依存度一直处于波动状态, 发展平稳, 但是2009年降幅较大

2000年至2008年，广东省的外贸进口依存度一直处于波动状态，发展平稳，维持在50\% 以上, 只有 2009 年低于 $50 \%$, 下降到 $43.6280 \%$, 说明广东省在实施外向型经济发展战略过程 中, 出口与进口并重, 为广东省经济的可持续发展提供保障。

\section{3 利用外资发展现状及特征}

1、协议利用外资水平高，但2008年后下降幅度大

2000年广东省签订利用外资协议(合同) 16879个，2009年签订5693个，比2008年减少了 $36.60 \%$ 。虽然签订利用外资协议(合同) 数目有所减少，但是协议利用外资额确在不断增长， 由2000年的110.86亿美元增至2008年的307.14亿美元，由于金融危机的不利因素，2009年协议 利用外资额比2008年减少了 $37.91 \% ，$ 如表1所示。

表1 广东省近几年利用外资情况

\begin{tabular}{c|c|c|c|c|c}
\hline 指标 & 2000 & 2005 & 2008 & 2009 & 2009比2008增长 $(\%)$ \\
\hline 签订利用外资协议(合同) (个) & 16879 & 11786 & 8980 & 5693 & -36.60 \\
\hline 外商直接投资 (个) & 4245 & 8384 & 6999 & 4346 & -37.91 \\
\hline 签订利用外资协议(合同) & 110.86 & 267.57 & 307.14 & 182.41 & -40.61 \\
\hline 外商直接投资（亿美元） & 86.84 & 237.44 & 286.4 & 175.58 & -38.69 \\
\hline 实际利用外资额(亿美元) & 145.75 & 151.74 & 212.67 & 202.87 & -4.61 \\
\hline 外商直接投资（亿美元） & 122.37 & 123.64 & 191.67 & 195.35 & 1.919967 \\
\hline
\end{tabular}

2、实际利用外资规模保持较高水平

2000 年广东省实际利用外资额为 145.75 亿美元，2008年增加到 212.67 亿美元，增长了 $45.91 \%$, 其中 2000 年外商直接投资总额为 122.37 亿美元, 2008年增加到191.67亿美元, 增长了 $56.63 \%$, 实际利用外资额 2009 年比 2008 年下降了 $4.61 \%$ 。

\section{5. 对策建议}

进入新世纪以来，广东省国民经济取得了长足发展，但我们也应看到面临的巨大挑战。 为有效应对面临的机遇和挑战, 保持我省外向型经济健康、快速发展, 现提出以下对策建议。 


\section{（一）统筹国内国际两个市场}

我们应当制定科学的发展战略，统筹国内国际两个市场，充分利用国内国际两种资源。 一是要积极扩大国内市场。应当积极引导外贸企业制定灵活的经营战略, 抓住国内消费迅速 增长的有利时机, 找准企业的市场定位, 开发适合国内消费者的产品。二是要坚持出口市场 多元化，避免对单个或少数主要市场的过度依赖。

（二）改善贸易结构，提高贸易商品品质

提高出口商品的质量, 把发展的重点从量的扩张转移到质的提高上, 加大品牌建设力度, 提高自主品牌的知名度; 增强贸易商品的科技含量, 将新一轮国内投资引导到以科技创新为 核心的产业结构升级上去, 提高企业的国际竞争力; 注重对外经济关系中的长远利益, 提前 布局产业格局，避免陷入比较优势陷阱，避免比较优势弱化对外向型经济的不利影响。

（三）鼓励私营企业发展

广东省私营企业发展迅速，成为推动广东经济较快发展的主要力量，私营企业出口总值 所占比重由 2000 年的 $0.67 \%$ 殺升至2009年的 $19.97 \%$, 在出口中的作用越来越大。所以, 我们 要积极鼓励私营企业发展, 继续加强私营企业的体制创新和机制创新, 切实提高私营企业的 管理水平, 加快私营企业的产业结构调整, 着力提高私营企业的自主创新能力, 积极推进私 营企业向外拓展，优化环境，为私营企业发展创造条件。

（四）加大国际化人才培养力度

市场的竞争说到底是人才的竞争, 要加强培养具有世界眼光、熟悉国际规则的外向型经 济领导人才, 具有国际经营先进理念的国际化经营管理人才, 熟悉国际贸易规则、善于应对 国际贸易纠纷的国际法律人才，以及国际投资、国际金融、国际市场营销等方面的专门人才。

\section{References}

[1] Yinglong Zheng, Information industry system guide and drive the development of export-oriented economy of Guangdong, Guangdong academy of social sciences, vol.01, pp. 162-163, 1988.

[2] Hong Wang, Guangdong export-oriented economy transformation under the background of the status of foreign direct investment and investment strategy adjustment, Journal of Lanzhou, vol.11, pp. 77-80, 2009.

[3] Zhigang Qiu, Theory of Guangdong foreign financial in the development of export-oriented economy, Guangdong finance, vol.10, pp. 17-19, 1989.

[4] Shouhong Xie, Regional differences and countermeasures of the development of export-oriented economy in Guangdong, Soft Science, vol.03, pp. 41-45, 2003.

[5] Jinshan Shi, Some ideas about the development of export-oriented economy in Guangdong, ZhongKai Agricultural Technical College Journals, vol.02, pp. 15-19, 1996.

[6] Ping Chen,Kai Li, The RMB exchange rate change on the influence of the export-oriented economy in Guangdong:Based on the VAR model, International Economic Review, vol.01, pp. 48-51, 2008.

[7] Zuoping Tan, Shaozhi Zheng. Guangdong export-oriented economy development and macroeconomic regulation and control, The Planned Economy Research, vol.S2, pp. 56-57, 1990.

[8] Jun Wang, System transformation and development of export-oriented economy in Guangdong research, Journal of Sun Yat-sen University (Social science edition) , vol.06, pp. 14-24, 1997. 